\title{
MELATONIN REGULATES OXIDATIVE STRESS INITIATED BY FREUND'S COMPLETE ADJUVANT
}

\author{
Miroslav Pohanka ${ }^{1}$, Branislav Ruttkay-Nedecký2,3, Josef Fusek ${ }^{1}$, Vojtěch Adam ${ }^{2,3}$, René Kizek $^{2,3}$ \\ Faculty of Military Health Sciences, University of Defence, Hradec Králové, Czech Republic'; Central European Institute \\ of Technology, Brno University of Technology, Brno, Czech Republic²; Department of Chemistry and Biochemistry, Faculty \\ of Agronomy, Mendel University in Brno, Brno, Czech Republic ${ }^{3}$
}

\begin{abstract}
Summary: Melatonin is a hormone with strong antioxidant properties. In this experiment, Freund's complete adjuvant was used as a stressogenic substance given to laboratory outbred mice, whereas melatonin was investigated as a protectant against the stressogenic effect. Levels of low molecular weight antioxidants, thiobarbituric acid reactive substances, and tumor necrosis factor $\alpha$ and activity of glutathione reductase were determined in blood from the animals. Surprisingly, melatonin was not involved in direct regulation of antioxidants, thiobarbituric acid reactive substances and tumor necrosis factor $\alpha$. On the other hand, melatonin regulated glutathione reductase activity. We can conclude on regulation of metabolism caused by melatonin in the model. The effect was more important than the expected regulation of immunity and basal oxidative homeostasis.
\end{abstract}

Keywords: Antioxidant; Oxidative stress; Melatonin; Reactive oxygen species; Epiphysis; Hormone

\section{Introduction}

Melatonin is a hormone from pineal gland. Under physiological conditions, melatonin regulates circadian biological rhythms in vertebrates $(1,2)$ including mammals $(3,4)$. Currently, melatonin is not pharmacologically unknown compound as it is distributed like a drug or food supplement regulating sleep. Clinical trials on melatonin applications are running as well $(5,6)$.

Beside hormonal effect, melatonin is known for its ability to quench reactive oxygen and nitrogen species in course of its antioxidant effect (7). Melatonin is called terminal or suicidal antioxidant that indicates irreversible process of the molecule oxidation. Not only melatonin but also products of melatonin's oxidation, 6-hydroxymelatonin, 3-hydroxymelatonin and $\mathrm{N}$-acetyl-N-formyl-5-methoxykynurenamine, are also antioxidants $(8,9)$. Because of the antioxidant properties, melatonin can be considered as a compound suitable for suppression of oxidative stress and generation of reactive oxygen and nitrogen species.

In the present manuscript, melatonin was chosen as a low molecular weight antioxidant able to reduce initiated oxidative stress caused by Freund's complete adjuvant. The adjuvant is typically used in immunization experiments because it is able to pronounce immunity response. However, the adjuvant is also effective enough to initiate oxidative stress in animal models (10-13). Because melatonin is a strong antioxidant, we assume that it will be potent enough to resolve oxidative stress initiated by Freund's complete adjuvant. Efficacy of melatonin to suppress oxidative stress is hypothesized and researched in this paper.

\section{Material and Methods}

\section{Experiment on laboratory animals}

In a total, 600 female mice (standard white outbred, ICR, strain) were purchased from Velaz (Unetice, Czech Republic) and they used in the experiment. The eight weeks old mice weighted $18 \pm 2 \mathrm{~g}$. Manipulation with the animals as well as the whole experiment were permitted and supervised by the ethical committee at Faculty of Military Health Sciences (Hradec Kralove, Czech Republic). The mice were accommodated in an animal house with temperature $22 \pm 2{ }^{\circ} \mathrm{C}$, humidity $50 \pm 10 \%$ and light/dark period each 12 hours provided during the whole experiment.

Prior to the experiment beginning, melatonin (grade for analytical purposes) and Freund's complete adjuvant were received from Sigma-Aldrich (Saint Louis, Missouri, USA). Freund's complete adjuvant had standard composition $1 \mathrm{mg}$ of Mycobacterium tuberculosis (H 37RA; American type of culture collection 25177) per $0.85 \mathrm{ml}$ of paraffin oil and $0.15 \mathrm{ml}$ mannide monooleate.

The animals were divided into 15 groups each 40 animals. First group served as a control and the animals 
received $100 \mu$ l saline only. The second and third groups received Freund's complete adjuvant in an amount $20 \mu 1$ respective $50 \mu \mathrm{l}$ per an animal. Fourth to seventh groups received melatonin (in a dose $1-10-100-1000 \mu \mathrm{g} / \mathrm{kg}$ of body weight). Melatonin was applied as a solution in saline in total volume $100 \mu \mathrm{l}$. Animals in the eight to eleventh groups received the same dose of melatonin like above; however, the animals received $20 \mu \mathrm{l}$ of Freund's complete adjuvant as well. The last four groups (12-15) had also dose of melatonin $1-10-100-1000 \mu \mathrm{g} / \mathrm{kg}$ but they were exposed to $50 \mu \mathrm{l}$ of Freund's complete adjuvant. The both melatonin and the adjuvant were given intramuscularly into rear limb. 10 animals from each group was sacrificed one day after experiment beginning. Another 10 animals per a day were sacrificed in second, third and fourth day. The sacrificing was done under $\mathrm{CO}_{2}$ anesthesia by cutting of jugular vein and blood was collected into tubes with lithium heparin (Dialab, Prague, Czech Republic). Blood was centrifuged at $1,000 \times \mathrm{g}$ for 5 minutes and plasma was separated from mass of erythrocytes.

\section{Ex vivo assays}

Low molecular weight antioxidants were assayed using Ferric Reducing Antioxidant Power (FRAP) method, Free Radicals (FR) method, chromatography of reduced (GSH) and oxidized (GSSG) glutathione, and 2,2-diphenyl-1-picrylhydrazyl (DPPH) method. The assays were done in compliance with the referred papers $(14,15)$. Level of malondialdehyde was measured by Thiobarbituric Acid Reactive Substances (TBARS) method in compliance with the referred protocols $(14,15)$. Glutathione reductase (GR) assays was performed earlier and the quoted protocols were used here $(16,17)$. Level of tumor necrosis factor alpha (TNF- $\alpha$ ) in plasma was assayed using indirect Enzyme Linked Immunosorbent Assay (ELISA) kit by Sigma-Aldrich.

\section{Statistics}

The achieved experimental data were processed by Origin 8 Pro (OriginLab Corporation, Northampton, MA, USA) software. One-way ANOVA with Bonferroni test were applied and significance of differences between experimental groups $(\mathrm{n}=10)$ was tested on probability levels P 0.05 and 0.01 .

\section{Results and Discussion}

During the experiment, no decease occurred prior to euthanasia. The animals had normal behavior and no visual difference between the tested groups was found. Examination of plasmatic TNF- $\alpha$ did not show the significant effect of melatonin either alone or its effect to modulation of inflammation initiated by Freund's complete adjuvant. This is a surprising finding because an anti-inflammatory effect of melatonin was expected regarding to cited literature (9, 18, 19). Freund's complete adjuvant causes inflammatory reaction as obvious from Figure 1. The effect was increasing during the time of experiment and level of TNF $\alpha$ was doubled in the end of experiment when compared to the controls. The increase of TNF $\alpha$ was in dose response manner as well which emphasized plausibility of the finding. On the other hand, the increase was not extensive enough to be comparable with inflammation during serious initialization of immune system during infections or sepsis (20). It can be reason why effect melatonin on TNF $\alpha$ was not revealed.

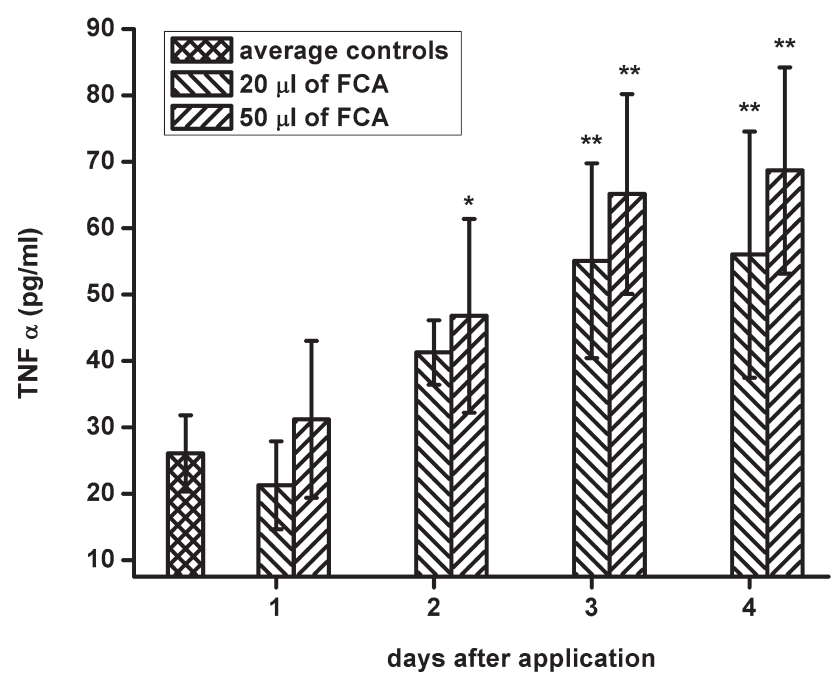

Fig. 1: Level of tumor necrosis factor $\alpha(\mathrm{TNF} \alpha)$ in plasma of mice treated with Freund's complete adjuvant (FCA). Error bars indicate standard deviation for $\mathrm{n}=10$. Significance against controls is marked by * respective ${ }^{* *}$ for significance level 0.05 respective 0.01 .

In the tested blood cells, significant effect of melatonin on glutathione reductase activity was proved (Table 1). No significant effect of the both Freund's complete adjuvant and melatonin on glutathione reductase activity was proved in animals sacrificed one respective two days after experiment beginning. Freund's complete adjuvant caused significant increase of glutathione reductase level in blood cells three and four days after experiment beginning. Melatonin significantly reduced the increase of glutathione reductase level caused by Freund's complete adjuvant. Except of the lowest dose $1 \mathrm{mg} / \mathrm{kg}$, melatonin returned glutathione reductase activity to level insignificant to the controls; however, some minor and insignificant increase was observed even for the highest doses of melatonin. Glutathione reductase is an enzyme involved in protection against oxidative stress and its activity is typically increased during stress conditions (21-23). The data can be interpreted as a proved stressogenic effect of Freund's complete adjuvant and amelioration of the effect by melatonin. 
Tab. 1: Glutathione reductase activity values (kat/g) in blood cells.

\begin{tabular}{|l|c|c|c|c|}
\hline Group & Day 1 & Day 2 & Day 3 & Day 4 \\
\hline controls & $3.76 \pm 0.31$ & $3.62 \pm 0.38$ & $3.78 \pm 0.22$ & $3.82 \pm 0.25$ \\
\hline FCA $-20 \mu \mathrm{l}$ & $3.79 \pm 0.33$ & $3.81 \pm 0.41$ & $4.30 \pm 0.34(* *)$ & $4.36 \pm 0.30(*)$ \\
\hline FCA $-50 \mu 1$ & $3.69 \pm 0.29$ & $3.83 \pm 0.36$ & $4.34 \pm 0.43(* *)$ & $4.52 \pm 0.55(* *)$ \\
\hline M $1 \mu \mathrm{g} / \mathrm{kg}$ & $3.81 \pm 0.31$ & $3.81 \pm 0.21$ & $3.81 \pm 0.24$ & $3.71 \pm 0.32$ \\
\hline $\mathrm{M} 10 \mu \mathrm{g} / \mathrm{kg}$ & $3.77 \pm 0.24$ & $3.83 \pm 0.36$ & $3.79 \pm 0.26$ & $4.00 \pm 0.39$ \\
\hline $\mathrm{M} 100 \mu \mathrm{g} / \mathrm{kg}$ & $3.82 \pm 0.25$ & $3.87 \pm 0.29$ & $3.85 \pm 0.30$ & $3.75 \pm 0.32$ \\
\hline $\mathrm{M} 1000 \mu \mathrm{g} / \mathrm{kg}$ & $3.79 \pm 0.35$ & $3.92 \pm 0.15$ & $3.92 \pm 0.20$ & $3.94 \pm 0.25$ \\
\hline $\mathrm{M} 1 \mu \mathrm{g} / \mathrm{kg}+\mathrm{FCA}-20 \mu 1$ & $3.86 \pm 0.31$ & $3.80 \pm 0.26$ & $4.26 \pm 0.37(*)$ & $4.41 \pm 0.34(*)$ \\
\hline $\mathrm{M} 10 \mu \mathrm{g} / \mathrm{kg}+\mathrm{FCA}-20 \mu 1$ & $3.87 \pm 0.44$ & $3.77 \pm 0.22$ & $3.95 \pm 0.22$ & $4.24 \pm 0.43$ \\
\hline $\mathrm{M} 100 \mu \mathrm{g} / \mathrm{kg}+\mathrm{FCA}-20 \mu \mathrm{l}$ & $3.81 \pm 0.24$ & $3.74 \pm 0.18$ & $3.87 \pm 0.21$ & $4.12 \pm 0.36$ \\
\hline $\mathrm{M} 1000 \mu \mathrm{g} / \mathrm{kg}+\mathrm{FCA}-20 \mu 1$ & $3.78 \pm 0.22$ & $3.84 \pm 0.23$ & $3.98 \pm 0.27$ & $3.82 \pm 0.24$ \\
\hline $\mathrm{M} 1 \mu \mathrm{g} / \mathrm{kg}+\mathrm{FCA}-50 \mu 1$ & $3.81 \pm 0.24$ & $3.85 \pm 0.27$ & $4.25 \pm 0.31(*)$ & $4.50 \pm 0.54(* *)$ \\
\hline $\mathrm{M} 10 \mu \mathrm{g} / \mathrm{kg}+\mathrm{FCA}-50 \mu 1$ & $3.75 \pm 0.29$ & $3.76 \pm 0.19$ & $3.98 \pm 0.27$ & $4.40 \pm 0.31$ \\
\hline $\mathrm{M} 100 \mu \mathrm{g} / \mathrm{kg}+\mathrm{FCA}-50 \mu \mathrm{l}$ & $3.85 \pm 0.24$ & $3.88 \pm 0.23$ & $3.83 \pm 0.24$ & $4.23 \pm 0.40$ \\
\hline $\mathrm{M} 1000 \mu \mathrm{g} / \mathrm{kg}+\mathrm{FCA}-50 \mu \mathrm{l}$ & $3.94 \pm 0.25$ & $3.92 \pm 0.31$ & $3.89 \pm 0.32$ & $3.96 \pm 0.41$ \\
\hline
\end{tabular}

$\mathrm{M}$ - melatonin; FCA - Freund's complete adjuvant; significance against controls: * $(\mathrm{P}=0.05)$ and ** $(\mathrm{P}=0.01)$

Tests for low molecular weight antioxidants including GSH/GSSG levels and test for TBARS indicating peroxidation of lipids did not bring a significant change (data not shown). Low molecular weight antioxidants are necessary for covering of oxidative stress as they can directly react with reactive oxygen species $(24,25)$. GSH/GSSG levels and their ration have an important value as well (26). TBARS level serves as a direct proof of lipid peroxidation resulting in creation of malondialdehyde $(27,28)$. The TBARS value becomes typically increased once an oxidative insult is uncovered by antioxidants $(29,30)$. Owing to the experimental data, we can infer that Freund's complete adjuvant caused stressogenic effect; however, the effect was not extensive enough to causes uncovered oxidative insult (regarding to TBARS value) or depletion of antioxidants. Melatonin did not worsen oxidative balance despite it has significant role in decrease of glutathione reductase activity. It seems that melatonin suppressed the stressogenic effect of Freund's complete adjuvant by another way than regulation of immunity or direct effect on low molecular weight antioxidants. Considering examination of TBARS and low molecular weight antioxidants in the blood, melatonin acts as an anti-stressogenic rather than stressogenic compound. The effect is, however, hardly traceable.

It is not clear how melatonin influences level of glutathione reductase. It is probably not based on its antioxidant properties because it has no effect on low molecular weight antioxidant homeostasis. Regulation of metabolism is probably the more plausible hypothesis. Impact of melatonin on enzymes including antioxidant enzymes was reported in some works (31). It is also potent to enhance adipose tissue (32) and even basic metabolism via glucose (33). Metabolizing of Freund's complete adjuvant can be considered as a melatonin effect proved here. The antioxidant effect of melatonin revealed in this experiment is actually based on detoxification rather than common involvement in antioxidant barriers.

\section{Conclusion}

Melatonin is the both a low molecular weight antioxidant and a hormone. In the present experiment, we proved regulatory effect of melatonin during mild stressogenic conditions. It appears that melatonin was able to modulate stressogenic reaction by metabolism rather than direct involvement in regulation of immunity or antioxidant barriers.

\section{References}

1. Ivanova TN, Iuvone PM. Melatonin synthesis in retina: circadian regulation of arylalkylamine $\mathrm{N}$-acetyltransferase activity in cultured photoreceptor cells of embryonic chicken retina. Brain Res 2003; 973(1): 56-63.

2. do Carmo Buonfiglio D, Peliciari-Garcia RA, do Amaral FG et al. Early-stage retinal melatonin synthesis impairment in streptozotocin-induced diabetic wistar rats. Invest Ophthalml Vis Sci 2011; 52(10): 7416-22.

3. Marczynski TJ, Yamaguchi N, Ling GM, Grodzinska L. Sleep induced by the administration of melatonin (5-methoxyn-acetyltryptamine) to the hypothalamus in unrestrained cats. Experimentia 1964; 20(8): 435-7.

4. Dubocovich ML. Melatonin receptors: Role on sleep and circadian rhythm regulation. Sleep Med 2007; 8(Suppl3): S34-S42.

5. Hobson SR, Lim R, Gardiner EE, Alers NO, Wallace EM. Phase I pilot clinical trial of antenatal maternally administered melatonin to decrease the level of oxidative stress in human pregnancies affected by pre-eclampsia (PAMPR): study protocol. BMJ Open 2013; 3(9): e003788. 
6. Wilhelmsen-Langeland A, Saxvig IW, Pallesen S et al. A randomized controlled trial with bright light and melatonin for the treatment of delayed sleep phase disorder: effects on subjective and objective sleepiness and cognitive function. J Biol Rhythms 2013; 28(5): 306-21.

7. Pohanka M. Alzheimer's disease and related neurodegenerative disorders: implication and counteracting of melatonin. J Appl Biomed 2011; 9(4): 185-96.

8. Shirazi A, Ghobadi G, Ghazi-Khansari M. A radiobiological review on melatonin: a novel radioprotector. J Radiat Res. 2007; 48(4): 263-72.

9. Pohanka M. Impact of melatonin on immunity: a review. Cent Eur J Med 2013; 8(4): 369-76.

10. Navarro SA, Serafim KG, Mizokami SS, Hohmann MS, Casagrande R, Verri WA Nalgesic activity of piracetam: effect on cytokine production and oxidative stress. Pharmacol Biochem Behav 2013; doi: 10.1016/j.pbb.2013.02.018.

11. Kumar VL, Guruprasad B, Wahane VD. Atorvastatin exhibits anti-inflammatory and anti-oxidant properties in adjuvant-induced monoarthritis. Inflammopharmacology 2010; 18(6): 303-8.

12. Feketeova L, Jancova P, Moravcova P et al. Effect of methotrexate on inflammatory cells redistribution in experimental adjuvant arthritis. Rheumatol Int 2012; 32(11): 3517-23.

13. Macickova T, Drabikova K, Nosal R, Bauerova K, Mihalova D, Harmatha J et al. In vivo effect of pinosylvin and pterostilbene in the animal model of adjuvant arthritis. Neuroendocrinol Lett 2010; 21(S2): 91-5.

14. Pohanka M, Hynek D, Kracmarova A et al. Voltammetry Assay for Assessment of Oxidative Stress linked Pathologies in Brain Tumor suffered Childhood Patients. Int J Electrochem Sc 2012; 7(12): 11978-92.

15. Pohanka M, Sochor J, Ruttkay-Nedecky B et al. Automated assay of the potency of natural antioxidants using pipetting robot and spectrophotometry. J Appl Biomed 2012; 10(3): 155-67.

16. Pohanka M, Sobotka J, Stetina R. Sulfur mustard induced oxidative stress and its alteration by epigallocatechin gallate. Toxicol Lett 2011;201(2): 105-9.

17. Pohanka M, Sobotka J, Jilkova M, Stetina R. Oxidative stress after sulfur mustard intoxication and its reduction by melatonin: efficacy of antioxidant therapy during serious intoxication. Drug Chem Toxicol 2011; 34(1): 85-91.

18. Laliena A, San Miguel B, Crespo I, Alvarez M, Gonzalez-Gallego J, Tunon MJ. Melatonin attenuates inflammation and promotes regeneration in rabbits with fulminant hepatitis of viral origin. J Pineal Res 2012; 53(3): 270-8.

19. Kim JY, Lee YD, Kim BJ et al. Melatonin improves inflammatory cytokine profiles in lung inflammation associated with sleep deprivation. Mol Med Rep 2012; 5(5): $1281-4$

20. Kothari N, Bogra J, Abbas H et al. Tumor necrosis factor gene polymorphism results in high TNF level in sepsis and septic shock. Cytokine 2013; 61(2): 676-81.
21. Hubner-Wozniak E, Okecka-Szymanska J, Stupnicki R, Malara M, Kozdron E. Age-related blood antioxidant capacity in men and women. J Med Biochem 2011; 30(2): 103-8.

22. Kodydkova J, Vavrova L, Stankova B, Macasek J, Krechler T, Zak A. Antioxidant status and oxidative stress markers in pancreatic cancer and chronic pancreatitis. Pancreas 2013; 42(4): 614-21.

23. Rowinski R, Kozakiewicz M, Kedziora-Kornatowska K, Hubner-Wozniak E, Kedziora J. Markers of oxidative stress and erythrocyte antioxidant enzyme activity in older men and women with differing physical activity. Exp Gerontol 2013; 48(11): $1141-6$

24. Farias MS, Budni P, Ribeiro CM et al. Antioxidant supplementation attenuates oxidative stress in chronic hepatitis C patients. Gastroenterol Hepatol 2012; 35(6): 386-94.

25. Pohanka M. Antioxidants countermeasures against sulfur mustard. Mini Rev Med Chem 2012; 12(8): 742-8.

26. Khan $\mathrm{H}$, Khan MF, Jan SU, Ullah N. Effect of aluminium metal on glutathione (GSH) level in plasma and cytosolic fraction of human blood. Pak J Pharm Sci 2011; 24(1): 13-8.

27. Lomova MV, Sukhorukov GB, Antipina MN. Antioxidant coating of micronsize droplets for prevention of lipid peroxidation in oil-in-water reduction. ACS Appl Mat Interac 2010; 2(12): 3669-76.

28. Broniowska KA, Kirilyuk I, Wisniewska A. Spin-labelled lutein as a new antioxidant in protection against lipid peroxidation. Free Radical Res 2007; 41(9): 1053-60.

29. Zivkovic V, Jakovljevic V, Pechanova O et al. Effects of DL-homocysteine thiolactone on cardiac contractility, coronary flow, and oxidative stress markers in the isolated rat heart: the role of different gasotransmitters. Biomed Res Int 2013; 318471.

30. Puzserova A, Kopincova J, Slezak P, Balis P, Bernatova I. Endothelial dysfunction in femoral artery of the hypertensive rats is nitric oxide independent. Physiol Res 2013; 62(6): 615-29.

31. Fischer TW, Kleszczynski K, Hardkop LH, Kruse N, Zillikens D. Melatonin enhances antioxidative enzyme gene expression (CAT, GPx, SOD), prevents their UVR-induced depletion, and protects against the formation of DNA damage (8-hydroxy-2'-deoxyguanosine) in ex vivo human skin. J Pineal Res 2012; 54(3): 303-12.

32. Jimenez-Aranda A, Fernandez-Vazquez G, Campos D et al. Melatonin induces browning of inguinal white adipose tissue in Zucker diabetic fatty rats. J Pineal Res 2013; 55(4): 416-23.

33. Aqil A, Rosado I, Ruiz R, Fiqueroa A, Zen N, Fernandez-Vazquez G. Melatonin improves glucose homeostasis in young Zucker diabetic fatty rats. J Pineal Res 2012; 52(2): 203-10.

Received: $19 / 02 / 2015$

Accepted in revised form: $31 / 03 / 2015$

\section{Corresponding author:}

Miroslav Pohanka, Faculty of Military Health Sciences, University of Defence, Trebešská 1575, 50001 Hradec Králové, Czech Republic; e-mail: miroslav.pohanka@gmail.com 